\title{
Teaching Reform of data structure based on CDIO Educational Concept
}

\author{
Fengxia Yang \\ Department of Computer Science \\ Cangzhou Normal University \\ Cangzhou , China \\ szyfx@163.com
}

\begin{abstract}
Data structure is a strong theoretical and practical course, but the traditional teaching methods can not meet the demands of engineering personnel training. The author of this article introduces "learning in doing" and "project-based teaching and learning" based on CDIO educational concept to data structure teaching, attempting to reform the teaching contents, teaching methods and examination that achieve good results.
\end{abstract}

Keywords- CDIO educational concept; data structure; project; case)

\section{INTRODUCTION}

At present, the training of China's applied talents are emphasizing on theory that students rarely receive practical training in project and team work, and can not immediately adapt to the needs of the job after graduation, generally needed a long time of training. Mc.Kinsey Global Institute said in a report in October 2005, there are about 600,000 Chinese engineering graduates in 2005 , only less than $10 \%$ of whom are suitable for working in international companies. Therefore, exploring engineering education reform and seeking new modes and new methods of engineering teaching are becoming an important task for the educators.

CDIO with the advanced engineering education concept, the good practical operation, the comprehensive curriculum system, and the general personnel training mode wins the attention and favor of many higher engineering faculties ${ }^{[1 \sim 2]}$. The experience at home and abroad shows that the concepts and methods of CDIO are advanced perfectly suited to all aspects of engineering process of teaching the reform ${ }^{[3]}$. Educators in China combined with China's national conditions, introducing CDIO into our teaching, such as "EIP-CDIO" proposed by $\mathrm{Gu}$ Peihua, Shantou University ${ }^{[2]}$; "CIO-the CDIO" by Zhang Qi, Lishui College ${ }^{[4]}$; "CEC-CDIO" by $\mathrm{Hu}$ Zhenwen $^{[5]}$, Huo Junyi ${ }^{[6]}$, Shijiazhuang Railway vocational and Technical College. Tsinghua University reformed the data structures and algorithms, and the database systems principles of curriculum ${ }^{[7]}$ using the CDIO teaching methods. As a result, students' self-learning and the ability to solve practical problems, coordination and communication, teamwork ability have been greatly improved and the results are satisfied. Cangzhou Normal University is a local application-oriented college; and the positioning of Department of Computer Science is a feature-oriented training engineer in the region and surrounding areas. So it is suitable to adopt CDIO education concepts and evaluation criteria in the teaching. The author of this article has engaged in the data structure teaching for many years, studying deeply the data structure teaching content, teaching methods, evaluation based on CDIO education concepts.

\section{CDIO EDUCATION CONCEPT}

CDIO is led by Massachusetts Institute of Technology (MIT) and dozens of well-known universities around the world advocating of modern engineering education framework that are Conceive, Design, Implement, and Operate which are the centralized summarization and abstract expression of "learning in doing" and "project-based teaching and learning"[8]. CDIO education concept makes good use of College's full disciplines and rich learning materials as the condition, as close as possible to the actual engineering referring to technology, economics, business and social as the main carrier. Connecting with professional core courses teaching, students are able to learn engineering with the active, practical, and organic links between courses to cultivate the students' engineering capacity ${ }^{[9]}$. The basic contents of CDIO probably can be summarized as follows: one vision, one outline, 12 principles and 5 guidelines.

\section{CURRENT ANALYSIS OF DATA STRUCTURE TEACHING}

Data structure is one of the most important core courses in the computer science curriculum system, providing a solid theoretical foundation for the study of various subjects that plays a nexus role. For the applied undergraduate colleges, the teaching aims focus on the algorithm implementation of data structure on the basis of logical structure, storage structure and the specific structure, focusing on the characteristics of structure, the efficiency of algorithm, the application of selecting structures and algorithms in the real problems that lay the foundation for learning operation system, encoding principles and the principles and application of database.

The course has strong theory, abstract concept, and classic complex algorithm, causing the phenomenon of "bi-difficulty" that are teachers struggling to teach, and students struggling to learn. Summarizing the teaching experiences, the data structure teaching with traditional concept has the following problems:

- Students have not enough understanding to the importance of algorithms and software design of computer science of this course, lacking of learning's interest and motivation. 
- In the curriculum theory, there are more knowledge and abstract algorithm, so students are relatively vague in the correlation between knowledge.

- In the practical teaching, confirmatory contents are more, but designment, comprehension and exploring innovation contents are less than normal. The cultivation of students' programming ability are emphasized but the cultivation of students' ability of communication, interaction and teamwork are ignored that causes to poor the students' vocational skills, teamwork and communication ability.

- Students lack of the ability of self-learning and independent practice. Students are over-reliance on the teacher's class teaching, lacking of the initiative consciousness to explore learning from perspective of solving problems.

In view of the existing problems, the reform of data structure teaching is imminent, because the data structure is not adopted, it will directly affect the its subsequent course learning. We refer to CDIO teaching concepts and follow the principle of applying the existing resources better and improving students' learning ability. Based on the characteristics of the data structures course a teaching mode is designed that is a comprehensive reform attempt to the data structures course teaching.

\section{DATA StRucture TEACHING REFORM BASED ON CDIO EDUCATION CONCEPT}

CDIO teaching concept systematically proposes 12 standards (Table 1) of ability cultivation, comprehensive implementation and checking evaluation. In the course construction, "learning in doing" and "teaching in doing" of course are achieved by conceive, design, implement, and operate of the project and case.

TABLE I. CDIO STANDARD

\begin{tabular}{|l|l|c|c|}
\hline 1 & Adopting CDIO Concept * & 7 & $\begin{array}{c}\text { Integration of teaching } \\
\text { plan* }\end{array}$ \\
\hline 2 & Learning effect* & 8 & Initiative learning \\
\hline 3 & $\begin{array}{l}\text { Integration of teaching } \\
\text { plan* }\end{array}$ & 9 & $\begin{array}{c}\text { Improvement of } \\
\text { Teachers' CDIO ability } *\end{array}$ \\
\hline 4 & $\begin{array}{l}\text { Introduction of project } \\
\text { Experience of design and } \\
\text { manufacture* }\end{array}$ & 10 & $\begin{array}{c}\text { Improvement of teachers' } \\
\text { teaching ability }\end{array}$ \\
\hline 6 & $\begin{array}{l}\text { CDIO students practice } \\
\text { places }\end{array}$ & 12 & $\begin{array}{c}\text { CDIO ability exam* profession } \\
\text { evaluation }\end{array}$ \\
\hline
\end{tabular}

\section{A. Teaching contents reform}

1)Theory teaching: Data Sructures (C language version) by Yan Weimin, published by Tsinghua University Press, is rich in content, clear in structured system concept, and easy to understand, so we choose this book as the main materials, adopting the project-driven teaching method and the Case Study Method doing the teaching in accordance with the actual software development methods and steps to reach the CDIO standards 2.

In accordance with the standard 1 in CDIO, in order to allow students to receive CDIO-oriented project teaching methods and to actively participate in the learning process, in the first week college shall introduce the concept, pattern and advantages of CDIO leading to students fully understanding the difference between "learning in doing, teaching in doing" based on CDIO concept and "Centering with teachers and textbooks" based on traditional concept. At the beginning of this course, it is not hurry to introduce the theory, but is the emphasis on the application. Let students find the materials with their spare time, and understand the application of data structures in typical software that can stimulate students' interest and curiosity about learning .

In accordance with Standard 3 and Standard 4 of CDIO, in the teaching process, teachers not rigidly adhering to the syntax details, mainly enable students to understand and grasp the essence of data structure principles, using the method of succinct training and a point to an area explain the typical case and projects should be focused keys, coherent content and moderate difficulty. In the whole process, teachers should have higher CDIO teaching ability to CDIO standards 9 and 10 . Appropriate projects and case make the abstract theoretical knowledge becoming interesting, easy for students to understand and accept that is able to make up the disadvantages of "centered with teaching materials ". While it can enhance students' practical ability and adaptability, equipping with the ability to solve the practical engineering problems, to achieve the requirements of CDIO standards 7 and 8.

2)Experiment Teaching: Theoretical course of the data structure is very strong, but the function of the theoretical knowledge can effectively play only through practice, otherwise it is only a dream. So rich practical projects shall be set up in the teaching process to achieve the purposes of not only improving the students' ability but also deepening learning the basics.

Data structure courses do not have obvious integrity and the various data structures relatively are independent, therefore the experiment is divided into two major types: validation experiment and comprehensive design experiment. Validation experiment is focused on the single data structure for basic training, such as the operational achievement of linear storage and linked list storage, and the basic computing experiment, sequence and search, aiming to strengthen the basic knowledge, and to emphasize the normative and modular thinking. Comprehensive design experiment is to apply its theory to solve the practical problems, and to expand training such as solving the maze, the small text editor, dinning in queue in canteen, courier companies transporting goods, campus navigation, library management system and so on, aiming to develop students' innovation consciousness, practical ability, active learning, and organizational ability. "Students centering and teachers aiding” mode is adopted. The project plan, the implementation records and the stage results summarized are required, and with the combination of the teachers evaluation based on students performance and the students' selfassessment each other, students' CDIO activities achievements 
are evaluated. By the experimental teaching, the student's practical ability has been improved and the innovation strengthened that achieved the requirements of CDIO Standards 5 and 6.

Implementing methods of experimental teaching: confirmatory experiment requires that each student must be independent. The comprehensive design experiment adopts the group of every 4 to 6 persons, the members of whom work together to complete the experiment project, including needs analysis, algorithm design, coding, testing and so on. Each group elects a leader responsible for the organization. In the project implementing process, the students will participate and collaborate, allowing students to experience the real engineers' experience in their careers, in which the students effectively exercise the ability of communication and cooperation, solving problems and innovation thinking. At the same time, students' theory connecting with practice capacity, and many other capabilities of comprehensive application have been effectively exercised that lay a solid foundation for competing the future work.

The practice shows that the effects of experiment teaching are better than normal with the CDIO concept. Table 2 as follows:

TABLE II. CONTRAST BETWEEN CDIO MODEL AND TRADITIONAL MODEL

\begin{tabular}{|l|l|l|}
\hline \multicolumn{1}{|c|}{$\begin{array}{c}\text { Teaching } \\
\text { model }\end{array}$} & \multicolumn{1}{c|}{$\begin{array}{c}\text { Traditional } \\
\text { model }\end{array}$} & \multicolumn{1}{|c|}{ CDIO model } \\
\hline Experiment title & Same title & Select or conceive title \\
\hline $\begin{array}{l}\text { Finding } \\
\text { materials }\end{array}$ & less & $\begin{array}{l}\text { Finding a lot amount of } \\
\text { materials }\end{array}$ \\
\hline interest & less & more \\
\hline $\begin{array}{l}\text { Work } \\
\text { assignment }\end{array}$ & $\begin{array}{l}\text { Independent done } \\
\text { (plagiarism) }\end{array}$ & $\begin{array}{l}\text { Work assignment ( no } \\
\text { plagiarism ) }\end{array}$ \\
\hline file & Only code & File sound \\
\hline innovation & Little innovation & Some innovation \\
\hline
\end{tabular}

3)General Education : The cultivation of undergraduate applied talents should adhere to the general education guidance, both emphasizing the breadth of knowledge, but also focusing the depth of of knowledge. The purpose of CDIO engineering education concept is to cultivate students' engineering capabilities, not only including the academic knowledge, but also the students' life-long learning capability, team communication capability and the capability of ConceiveDesign - Implementation- Operate in the environment of enterprises and society. Therefore we can say that the aim of CDIO is to cultivate the general education values which integrate the professional basic theory and practical operational capability individual knowledge, experience and value system and teamwork spirit and communication ability.

\section{B. Reform of Teaching Method}

CDIO education mode is the centralized generation and abstract expression of "learning in doing" and "project-based teaching and learning". "Learning in doing" is an educational principle proposed by John Dewey, a famous education theorist, reflecting the combination of learning and doing, book knowledge and its application in real life. "Project-based learning” is for students to learn projects actively and practically by projects. Therefore, in the teaching process of data structure, the project-driven teaching methods and the case study methods are adopted, and the CDIO teaching concepts are integrated organically into the case explanation and implementation. The selection of cases and projects is follow the following principles:

1)Close to life, moderate difficulty: The selection of projects and cases is close to life, not only considering the students' interest, but also taking into account the difficulty of implementation aiming to enable students to understand the data structures and how close to their lives. For example: "Fox catching Rabbit" game as the linear case; operation of the printer the parking, management of the vehicles, and dinning in queue in canteen as the queuing case; courier companies transporting goods as the shortest path cases. Because the cases are close to life, the dull theories becomes lively and easy to understand that dispel the fear of students and mobilize the enthusiasm for learning.

2)Close to reality, learning to use: In learning a course, students are often concerned about the course which has how much effect in their future work that is which problems in the real life can be solved. Therefore, in teaching, the life image cases shall be introduced in addition to some really available software development projects, so that students can understand how to apply the data structure in the actual programming. Considering the students' characteristics of searching and playing games in the Internet, we can take the data structure in game programming as a practical project. For example: "Lianliankan” game involves solving the shortest path between the same graphics as the shortest path map project; the reflection of "monster" in "Fight with Zombies" game involves the construction of the Huffman tree, as a decision tree algorithm projects; the search engine is related to the string to find and match as the string to find and match items; the design of the database management system to the B-tree lookup as the B-tree search algorithm. In the process of completing these projects, students deepen the understanding of knowledge application, and more important the students identify the direction of future learning and understand learning to use.

3)Take into account the links between the courses, forming disciplines mainline: Data structure plays a connecting role in the computer science curriculum system. If the projects and cases selected can be linked with other courses, then we can help students form a discipline mainline. The first course in data structure is programming language, such as $\mathrm{C}$ language. The student's language base is not very good, so the language contents shall be remedied in the teaching of data structure. Tutorial can not be used as a separate part, but taken naturally when it is needed, such as the dynamic memory allocation and the use of compass can be added in teaching linear chapter; the stack sections HANOR game tutorial recursive function calls, so as to learn the tree Figure chapters, recursive algorithm is very easy to read. Operating system and compiler theory are the successor courses of the data structure course, so in 
teaching the physical storage of data structure appropriate adds some memory, addressing modes and other contents. In this way, data structure, the first course and follow-up courses are linked organically to provide students a clear disciplines mainline in their mind.

\section{Reform of Evaluation Method}

The traditional way of evaluation is exam on paper, and the quality of teaching and students learning outcomes are evaluated by the marks. In one-hundred percentage system, marks on paper accounts for $70 \%$ of the final examination results, attendance, homework and experiments accounting for $30 \%$ of the final examination results. This evaluation method emphasizes more about results than process, in which students just before the final exam assault reviewing will be able to pass the exam which can not reflect the students' real learning process. Evaluation based on CDIO concept is the evaluation of the process, not only paying attention to the learning process of knowledge and skills, but also focusing on practical aspects and application capabilities, so as to achieve the harmonization between knowledge and capabilities.

Specific ways: Different capacities are assessed in different ways. For example, theoretical knowledge is evaluated on paper, used to examine students' mastery of basic content of the curriculum and methods, marks accounting for $40 \%$ of the final. The capability related to CDIO is based on the actual situation in various forms, such as records, reports, self-assessment, inter-assessment, scores accounting for $60 \%$ of the final. Diversification of assessment methods makes the evaluation system more complete and reliable, reaching the requirements of the CDIO standards 11 and 12 .

\section{CONCLUSION}

Data structure is a strong theoretical and practical course, but the teaching methods and evaluation methods can not suitable to the requirements of cultivating personnels with the traditional concept. By introducing "learning in doing" and "project-based teaching and learning" based on CDIO concept into the data structure teaching, the teaching content, teaching methods and evaluation ways are reformed tentatively. By practice, the teaching effects have bee significantly improved, compared with the textbook-centered and teaching-centered teaching methods. The teaching methods based on CDIO concept, not only enable students to master the basic professional knowledge and skills, but also enhance the qualities required by the practitioners that plays a greatly active role for the graduates to work in the sustainable development society.

\section{REFERENCES}

[1] Xueyong Gu,’Linking.Theory and Practical CDIO:The Exploration of Innovative Engineering Education of Tsinghua University,”. Higher Education of Engineering Press, vol. 1, pp. 11-23,. 2009.

[2] Peihua Gu, Yiping Li, Minfen Shen,"Training Mode of Innovative Personnel Design-oriented EIP-CDIO,’China Higher Education, vol 3, pp. 47-49.,2009.

[3] Zhiqiang Wang, Ping Cai, Wenfeng Du,"Multimedia Applications Basic Courses Teaching Reform based on CDIO,"Computer Education, vo1 12, pp. 137-138.,2009.

[4] Qi Zhang, Qiliang Tang,”Research on Cultivation Modes of Higher Engineering Education CIO-CDIO,”Vocational and Education, vo1 3, pp. 32-34,2009.

[5] Zhenwen Hu,Hui Li, Fengping Chen.,"Construction and Implementation of Vocational Curriculum System based on CECCDIO Mode,"Vocational and Technical, vol 1, pp. 64-66,2009.

[6] Junyi Huo, Dongmei Wan, Huichao Jin,"Construction and Implementation of Electrical Automation Technology Professional Course System based on CEC-CDIO Mode,"Vocational and Technical Education,vol 26,pp. 20-22.,2009.

[7] Xuhui Chen, Keshou Wu, Chunyan Jiang,"Education Model of Computer Engineering Based on CDIO,"Computer Education,vol 18, pp. 141-143, 2010.

[8] Jianzhong Cha,"CDIO Mode based on “Learning in Doing,”. Higher Education of Engineering, vol 3, pp. 2-7,2008.

[9] Jianzhong Cha,"Engineering Education Reform Strategy of Economic Globalization,"Higher Education of Engineering, vol 1,pp. 21-27,. 2008.

[10] Weimin Yan, Weimin Wu,”Data Structures (C Language version) ,” Beijing: Tsinghua University Press, 1997. 